\title{
Effect of Developing Footwork Movement Patterns on Results of Games of Squash Young Players *Dr/ Ihab Saber Ismail Ismail
}

\section{Introduction}

The sport of squash requires fast movement on a court characterized by a small area. However, players' movements in this space exceed the movements of any player in the other racket sports. So, movement should be easy, fluency and agile to save effort on all games of the tournament. Also the correct movement is the basic positioning to perform all strikes properly since the suitable position provides the body with balance before and after hitting the ball until getting back in a balance form that allows the player to control the half court area.

Ahmed Sobhi (2004) emphasized that mastering foot work movements was the most important factor helped the player win as it was not possible to carry out any skill or planning task whether it was attacking or defensive except through good command of foot work movements playing the basic role during training and tournament (1:45).

Philip Yarrow (2010) suggested that whatever a high level of proficiency in basic strikes the player reached in the game and whatever a high physical level the player reached, all of that would not qualify him to compete without getting a high level of proficiency in foot work movements (10:17).

Riham Mahmoud (2008) emphasized that random foot work movements could cause the loss of many points during the game and perfect movements helped the player control the reins of the game. She indicated that programs of foot work movements should be considered (5:63).

Spont Y. Cros (2007) confirmed that $80 \%$ of technical faults occurring in performing squash shots resulted from lowering the quality of foot movements rather than techniques of performing shots and their

* Lecturer, Dept. of Theories and Applications of Racket Sports, Faculty of Physical Education for Boys, Zagazig University

Assiut Journal For Sport Science Arts 
motor descriptions and that could be illustrated as hits would not be effective i.e. precise in respect of direction unless the player existed in the proper position in time to meet the ball (11:62).

The research problem can be outlined in two main points, firstly: random movements in the court as young players do not know proper movements and there are no rated effective and scientific programs of foot movements characterized by accuracy and efficiency, however, such programs depend on experience rather than science, secondly: young players are lacking specific physical abilities for foot movements by focusing on other aspects and disregarding foot movements with the result that the young player becomes unable to continue to move correctly during the game.

While judging several games of young players and viewing games as a coach, the researcher has noticed that the process of foot movements was random and many points were lost as players were unable to reach the ball quickly and in balance, depletion of players' energy in the first game, inability to complete the game with the same efficiency due to fatigue and the lack of physical abilities of the player related to movements, falling in judging faults particularly penalties for not knowing to back and return techniques in proper lines leading in conclusion to loose points.

Therefore, the researcher decided to establish a suggested training program to develop movement patterns in young players and to know its effect on results of squash games.

\section{Research objectives}

The purpose of this research was to make a layout of a training program to develop footwork movement patterns to know the following: - The effect of developing physical abilities specified for footwork movement patterns on results of games of squash young players in the experimental group.

- Differences between the two post-measurements of the experimental and control groups in developing footwork movement patterns and results of games.

- The correlation between developing footwork movement patterns and the 
results of games of squash young players in the experimental group.

\section{Research hypotheses}

- There are significant differences at (0.05) level between the pre and postmeasurements in physical abilities specified for footwork movements and the results of games in the experimental group in favor of the postmeasurement.

- There are significant differences between the two post-measurements of the experimental an $\mathrm{d}$ control groups in footwork movement patterns and the results of games in favor of the postmeasurement of the experimental group.

- There is a correlation between developing footwork movement patterns and improving the results of games of squash young players in the experimental group.

- Terminology used in the research

- Footwork movements of squash players:

It is the ability of the player to move quickly and in balance from the mid court area (7) to the proper place and in suitable time and strength to hit the ball effectively to win a direct point, then returning to the mid court area once again safely and in balance $(2: 8)$.

\section{Research procedures \\ Research method}

The researcher used the experimental method as it was suitable for the type and nature of this research through the experimental layout using the pre and post-measurements of the experimental and control groups.

\section{Procedures}

The research people comprised of young players under 15 years in squash clubs in Cairo Governorate listed in records of Egyptian Squash Federation in 2015/2016 training season. The researcher selected the research sample intentionally from squash young players under 15 years from Tala'ea Al-Gaish Sporting Club of (5) young players as an experimental group, Wadi Degla Sporting Club of (5) young players as a control group in addition to a pilot study sample from AlMaadi Sporting Club of (5) young players totaling (15) young players. Table (1): shows classification of the research subject.

\section{Table (1)}


Classification of the research subject

\begin{tabular}{|c|c|c|c|c|c|}
\hline \multirow{2}{*}{ No. } & \multicolumn{4}{|c|}{ subject } & \multirow{2}{*}{ Program } \\
\hline & \multicolumn{2}{|c|}{ Type of the sample } & No. & Percentage & \\
\hline 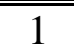 & \multicolumn{2}{|c|}{ Research pilot sample } & $\overline{5}$ & $33.33 \%$ & - \\
\hline 2 & \multirow{2}{*}{$\begin{array}{l}\text { Main } \\
\text { research } \\
\text { sample }\end{array}$} & $\begin{array}{l}\text { Experimental } \\
\text { group }\end{array}$ & 5 & $33.33 \%$ & $\begin{array}{c}\text { Suggested } \\
\text { program }\end{array}$ \\
\hline 3 & & $\begin{array}{l}\text { Control } \\
\text { group }\end{array}$ & 5 & $33.33 \%$ & $\begin{array}{l}\text { Suggested } \\
\text { program }\end{array}$ \\
\hline 4 & \multicolumn{2}{|c|}{ Total research sample } & 15 & $100 \%$ & - \\
\hline $\begin{array}{l}\text { tota } \\
\text { clas } \\
\text { perc } \\
\text { is } 6 \\
\text { of th } \\
\text { - H } \\
\text { sam }\end{array}$ & $\begin{array}{l}\text { Table } \\
\text { rese } \\
\text { ication } \\
\text { tage of } \\
67 \% \text { anc } \\
\text { pilot san } \\
\text { logeneity } \\
\text { e }\end{array}$ & $\begin{array}{l}\text { 1) indicate the } \\
\text { rch subject } \\
\text { and the } \\
\text { he main subject } \\
\text { the percentage } \\
\text { ple is } 33.33 \% \text {. } \\
\text { of the research }\end{array}$ & \multicolumn{3}{|c|}{$\begin{array}{l}\text { The researcher } \\
\text { computed the descriptive } \\
\text { statistics of the research subject } \\
\text { in variables of growth, tests of } \\
\text { physical abilities and footwork } \\
\text { movement patterns in Table } \\
\text { (2). }\end{array}$} \\
\hline
\end{tabular}

Table (2)

The descriptive statistics

\begin{tabular}{|c|c|c|c|c|c|c|}
\hline Variables & $\begin{array}{c}\text { Measuring } \\
\text { unit }\end{array}$ & $\mathbf{X}^{-}$ & $\mathbf{M}$ & SD & Kurtosis & Skewness \\
\hline Age & Year & $1 \leq . \mu 1$ & $1 \leqslant . \leqslant$. & 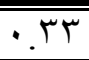 & $-\cdot .0 \mathrm{~V}$ & $-\cdot v \cdot$ \\
\hline Height & $\mathrm{cm}$ & 177.9. & 177.0. & 1.00 & $.7 \pi$ & $-\cdot . \wedge 7$ \\
\hline Weight & $\mathrm{kg}$ & 09.9. & $7 .$. & $r .1 T$ & $\because \cdot V$ & $-\cdot .71$ \\
\hline $\begin{array}{l}\text { Training } \\
\text { age }\end{array}$ & Year & 7.1. & 7. & $\cdot V \varepsilon$ & $-\cdot V \Gamma$ &.$- .1 V$ \\
\hline
\end{tabular}

Data in Table (2) show that values of skewness coefficients fall between $(-0.86$ and -0.17$)$ i.e. between ( 0 and +3 ) in variables of (age, height, weight, training age) indicating that the research subject individuals in such variables were homogeneous.

\section{Tools}


3- $\quad$ Test of agility for squash players to measure agility (11:53).

4- $\quad$ Test of speed endurance for squash players to measure speed endurance $(2: 126)$.

5- Test of speed of reaction for squash players to measure reaction $(2: 128)$.

6- Test of walk on an inverted Swedish bench to measure balance (2:129).

7- Measuring foot movements for squash players to measure footwork patterns (2:61).

Skill tests (results of games) (Attachment 1).

1- The researcher conducted a friendly championship at Hayat International Academy, AlTajamo Al-Khames, and Cairo to measure results of games of the experimental and control groups before and after the training program.

- Forms of recording data

The researcher schematized a data registration form for the research sample.

\section{Tools and apparatus used:}

Restameter to measure height, stopwatch, medical balance, ruler graduated in $(\mathrm{cm})$ to measure flexibility, Swedish bench, 2 squash courts, rackets and squash balls, labels.

\section{Pilot studies}

\section{First pilot study:}

The researcher carried out it on Saturday, (16/5/2015) to Monday, (18/5/2015) aiming at (practicing assistants, discovering failure and weakness aspects and how to avoid mistakes and defining time necessary for measuring process when executing tests and measurements, the rank of the conduct of tests).

\section{Second pilot study:}

The researcher carried out it with effect from Thursday, $\quad(21 / 5 / 2015)$ to Monday, (25/5/2015) aiming at computing scientific coefficients i.e. the validity and stability of tests as shown in Tables (3 \&4) showing scientific coefficients of tests of footwork movement patterns and results of games.

- The validity of tests

The researcher conducted out the validity of tests through the validity of differentiation method between two groups one of them was the differentiated group represented by young players under 15 years from Al-Shams 
Sporting club and the other group was the undifferentiated group represented by young players under 15 years from Maadi Sporting Club (the pilot research sample). Table (3) illustrates significance of differences between the differentiated and undifferentiated groups in tests of physical abilities under investigation.

Table (3)

Results of Mann -Whitney's test and value of $(U, Z)$ for the Tests validity $(\mathrm{n} 1=\mathrm{n} 2=5)$

\begin{tabular}{|c|c|c|c|c|c|c|c|}
\hline \multirow{2}{*}{ Tests } & \multicolumn{2}{|c|}{$\begin{array}{c}\text { Undifferentiated } \\
\text { group }\end{array}$} & \multicolumn{2}{|c|}{$\begin{array}{c}\text { Differentiated } \\
\text { group }\end{array}$} & \multirow{2}{*}{$\mathrm{U}$} & \multirow{2}{*}{\multicolumn{2}{|c|}{$\mathrm{Z}$}} \\
\hline & $\begin{array}{l}\text { Mean } \\
\text { ranks }\end{array}$ & $\begin{array}{l}\text { Total } \\
\text { ranks }\end{array}$ & $\begin{array}{l}\text { Mean } \\
\text { ranks }\end{array}$ & $\begin{array}{l}\text { Total } \\
\text { ranks }\end{array}$ & & & \\
\hline $1^{\mathrm{st}}$ & r... & $10 .$. & ^... & $\varepsilon \cdot \ldots$ & $\because \cdots$ & T.7r & Sig \\
\hline $2^{\text {nd }}$ & V. 9. & rq.o. & r. & 10.0. & $\because 0$. & Y.Or & Sig \\
\hline $3^{\text {rd }}$ & ^... & $\varepsilon \cdot \ldots$ & $r . .$. & $10 .$. & $\because \cdots$ & Y.7I & Sig \\
\hline $4^{\text {th }}$ & $r .$. & $10 .$. & ᄉ... & $\varepsilon \cdot \ldots$ & $\because \cdots$ & Y.7I & Sig \\
\hline $5^{\text {th }}$ & V.9. & rq.0. & r. & 10.0. & .0 . & 1.00 & $\mathrm{Sig}$ \\
\hline $6^{\text {th }}$ & $r .$. & $10 \ldots$ & ᄉ... & $\varepsilon \ldots$ & $\ldots$ & r. Tr & $\mathrm{Sig}$ \\
\hline $7^{\text {th }}$ & ^... & $\varepsilon \cdot \ldots$ & r... & $10 .$. & $\because \cdots$ & Y.Tr & Sig \\
\hline
\end{tabular}

Table (3) show that the value of computed $\mathrm{Z}$ is higher than that the tabulated (1.96) meaning that such tests are able to differentiate between levels and they are valid to measure characteristics for which they have been established.

The researcher conducted out the stability of the tests by applying and reapplying them to the pilot study sample with a time interval of 3 days (72hrs) between the first and the $2^{\text {nd }}$ applications. Table

illustrates stability coefficient between the first and the second applications to the pilot study in tests of physical abilities under investigation. 
Table (4)

Stability coefficient between the first and the second applications to the pilot sample in tests of physical abilities of footwork movement patterns under investigation $\mathrm{N}=5$

\begin{tabular}{|c|c|c|c|c|c|c|}
\hline \multirow{2}{*}{ Tests } & \multirow{2}{*}{$\begin{array}{c}\text { Measuring } \\
\text { units }\end{array}$} & \multicolumn{2}{|c|}{$\mathbf{1}^{\text {st }}$ application } & \multicolumn{2}{|c|}{$2^{\text {nd }}$ application } & \multirow{2}{*}{$r$} \\
\hline & & $\mathbf{x}^{-}$ & SD & $\mathbf{x}^{-}$ & SD & \\
\hline $1^{\text {st }}$ & $\mathrm{cm}$ & $\varepsilon \Sigma . \Sigma$ & r.9V & $\leqslant 0 . \leqslant$. & 1.01 & $.977 *$ \\
\hline $2^{\text {nd }}$ & Sec. & ov... & $r \leqslant 0$ & 07.5. & r.r. &.$\wedge \wedge \vee *$ \\
\hline $3^{\text {rd }}$ & Sec. & rוזי & דו & $r r . q$ & מץ. & $.9 \wedge \vee *$ \\
\hline $4^{\text {th }}$ & $\mathrm{cm}$ & $17 . \ldots$ & YY.TE & 101.7. & 11.0. & $.9 \leqslant 7 *$ \\
\hline $5^{\text {th }}$ & Sec. & 1.9. &.$\Gamma_{0}$ & $1 . \wedge r$ &.$\leqslant 0$ & $.97 \wedge *$ \\
\hline $6^{\text {th }}$ & No. & 10.Y. & I. & 10.1. &.$\wedge \varepsilon$ & $.97 \pi *$ \\
\hline $7^{\text {th }}$ & Sec. & VT. & $1 . r \varepsilon$ & $V \varepsilon . Y$. & 1.19 & $.9 \vee 9 *$ \\
\hline
\end{tabular}

Tabulated $(r){ }_{(3,0.05)}=0.878$

Table (4) illustrate that there is a significant correlation between scores of pilot study sample in the first and second applications of the physical tests as computed values of $(r)$ exceed that of the tabulated at significant live of (0.05) meaning that the scores of tests are stable when reapplied under the same circumstances.

The suggested training program Scientific fundamentals to establish the training program:

The researcher design the program through previous studies discussed the topic of footwork movements such as studies of Shawkat Jaber (2005) (6), Mamdouh Mohammed (2007)(9), Basem Mustafa (2008) (3) and Hamdy Aliwa (2010) (4). Footwork movement patterns were underlined according to the study of Riham Mahmoud (2008) (5), discussed an analytical study of important footwork movements in squash. The training program of footwork movements of the study of Ehab Saber (2013) (2). Bases of establishing the program:

- The training units were arranged from easy to difficult ones (severity - intensity) to suit the age and the physical level of young players in the research sample.

- The period of the suggested training program was underlined as (8) weeks.

- The number of daily training units in the week was 
determined by (3) training units.

Time of the training unit lasted 60 to $95 \mathrm{~min}$. without warming-up and conclusion. Time of warming- up lasted (15) min. and conclusion lasted (5) $\min$.

- The method of low and high interval training was defined for its using in the research.

- Weekly and interval load periods were identified by (1:2) i.e. one week for medium load followed by two weeks high load. From the $4^{\text {th }}$ week the weekly load periods were identified by (1:3) i.e. one week for medium load followed by 3 weeks high load. - The training load intensity was graded during the program as follows:

- $1^{\text {st }}$ week $50 \%$ of the level of the players (200 min.)

$2^{\text {nd }}$ week $10 \%$ increase for the time of the $1^{\text {st }}$ week (220 min.)

- $\quad 3^{\text {rd }}$ week $10 \%$ increase for the time of the $2^{\text {nd }}$ week (240 min.)

- $4^{\text {th }}$ week in time was equal to the time of the $2^{\text {nd }}$ week (220 min.)

- $\quad 5^{\text {th }}$ week in time was equal to the time of the $3^{\text {rd }}$ week (240 min.)

- $\quad 6^{\text {th }}$ week $10 \%$ increase for the time of :the $5^{\text {th }}$ week (255 min.)

- $\quad 7^{\text {th }}$ week (260 min.) $8^{\text {th }}$ week in time was equal to the time of the $4^{\text {th }}$ week (220 $\mathrm{min})$

The total time of the training program was (1855 min.) by (941 min.) for the physical part of footwork movement patterns by (60\%), (675 min.) to improve the skill part by $(30 \%)$, (239 $\mathrm{min}$.) to upgrade the level of planning performance by $(10 \%)$ using quick and slow interval training methods.

Steps of conducting the experiment:

The experiment was conducted according to the following steps:

- The place of applying the program was the squash court at Hayat International Academy, Al-Tajamo AlKhames.

- $\quad$ The suggested training program was applied during 2015/2016 training season.

- After underlining tests and measurements, tools and devices necessary for the research and selecting the sample scientifically and correctly, the researcher took some steps and procedures for the research that helped the experiment run scientifically and correctly as follows:

Pre-measurement:

The researcher applied the pre-measurement to the research sample as he applied physical tests under investigation on Tuesday, $26 / 5 / 2015$ then he set up a 
friendly championship on 28,29 \&30/5/2015.

Application of the program

After making sure that the research sample individuals were homogeneous, the researcher applied the training program to the research sample for two months during the period of general and special preparation with effect from Tuesday, 2/6/2015 to Sunday, $26 / 7 / 2015$ i.e. for (8) weeks by (3) training units a week on Sunday, Tuesday and Thursday every week.

Post-measurement:

It was carried out on the research sample with the same conditions, instructions, circumstances and descriptions of the pre-measurement after ending the period of applying the program on Thursday $28 / 7 / 2015$ and a friendly experimental championship on $1,2 \& 3 / 8 / 2015$.

Statistical treatments:

The researcher used in the statistical treatments of data of the current study the Statistical Package for Social Science (SPSS).

3/0 Presentation and discussion of results

Presentation of results

- Presentation of results of the $1^{\text {st }}$ hypothes

\section{Table (5)}

Significance of differences between means of ranks of degrees of the pre and post-measurements of the experimental group and the results of effect size using bilateral correlation coefficient of correlated pair ranks $\left(r_{\text {prb }}\right)$ and Eta square $\left(\eta^{2}\right)$ of results of footwork movement pattern $\mathrm{N}=5$

\begin{tabular}{|c|c|c|c|c|c|c|c|c|c|c|}
\hline \multirow{2}{*}{ Tests } & \multicolumn{3}{|c|}{ Negative ranks } & \multicolumn{3}{|c|}{ Positive ranks } & \multirow{2}{*}{\multicolumn{2}{|c|}{$\mathbf{Z}$}} & \multicolumn{2}{|c|}{$\begin{array}{c}\text { The size of } \\
\text { effect }\end{array}$} \\
\hline & No. & $\begin{array}{c}\text { Rank } \\
\mathrm{x}^{-}\end{array}$ & $\begin{array}{c}\text { Total } \\
\text { ranks }\end{array}$ & No. & $\begin{array}{c}\text { Rank } \\
\mathrm{x}^{-}\end{array}$ & $\begin{array}{c}\text { Total } \\
\text { ranks }\end{array}$ & & & $\left(\mathbf{r}_{\mathbf{p r b}}\right)$ & $\left(\eta^{2}\right)$ \\
\hline $1^{\mathrm{st}}$ & - & $\because \cdots$ & $\because \cdots$ & 0 & $r .$. & $10 \ldots$ & r.IT & Sig & 1.00 & $\because .90$ \\
\hline $2^{\text {nd }}$ & 0 & r... & $10 \ldots$ & . & $\because \cdots$ & $\because \cdots$ & $r .7$ & Sig. &.$\wedge$ & $\cdot .9 r$ \\
\hline $3^{\text {rd }}$ & 0 & $r .$. & $10 \ldots$ & . & $\because \cdots$ & $\because \cdots$ & $r . r$ & Sig &.$\wedge$. & .91 \\
\hline $4^{\text {th }}$ & $\cdot$ & $\because \cdots$ & $\because \cdots$ & 0 & $r .$. & $10 \ldots$ & $r .9$ & Sig. & 1.00 & .94 \\
\hline $5^{\text {th }}$ & 0 & r... & $10 \ldots$ & - & $\because \cdots$ & $\because \cdots$ & $r .4$ & Sig &.$\wedge$ & $\cdot .9 r$ \\
\hline $6^{\text {th }}$ & - & $\because \cdots$ & $\because \cdots$ & 0 & r... & $10 \ldots$ & $r . r$ & Sig. & 1.00 & $\because .9$. \\
\hline $7^{\text {th }}$ & 0 & r... & $10 \ldots$ & . & $\because \cdots$ & $\because \cdots$ & $r . r$ & Sig &.$\wedge$ & $\because .9$. \\
\hline $\begin{array}{l}\text { Results } \\
\text { of } \\
\text { games }\end{array}$ & - & $\because \cdots$ & $\because \cdots$ & 0 & r... & $10 \ldots$ & r.Ir & Sig. & 1.00 & .90 \\
\hline
\end{tabular}


Table (5) show that the value of computed $(\mathrm{Z})$ is higher than that the tabulated meaning that the value of Wilcoxon's test is statistically significant. It is clear that the size of effect $(r$ prb $)$ falls between $(0.80$ and 1.55) indicating that the effect size is strong to very strong and the value of $\left(\left(\eta^{2}\right)\right.$ falls between $(0.90$ and 0.95$)$ i.e. large effect size.

$3 / 1 / 2$ Presentation of results of the $2^{\text {nd }}$ hypothesis:

Table (6)

Significance of differences between means of ranks of degrees of the post-measurements of the experimental and the control groups and results of effect size using bilateral correlation coefficient of ranks $\left(r_{\text {prb }}\right)$ and Eta square $\left(\eta^{2}\right)$ of results of footwork movement patterns $n 1=n 2=5$

\begin{tabular}{|c|c|c|c|c|c|c|c|c|c|}
\hline \multirow{2}{*}{ Tests } & \multicolumn{2}{|c|}{$\begin{array}{l}\text { Experimental } \\
\text { group }\end{array}$} & \multicolumn{2}{|c|}{$\begin{array}{l}\text { Control } \\
\text { group }\end{array}$} & \multirow{2}{*}{$\mathbf{U}$} & \multirow{2}{*}{\multicolumn{2}{|c|}{$\mathbf{Z}$}} & \multicolumn{2}{|c|}{ Effect size } \\
\hline & $\begin{array}{c}\text { Rank } \\
\mathrm{x}^{-}\end{array}$ & $\begin{array}{l}\text { Total } \\
\text { ranks }\end{array}$ & $\begin{array}{c}\text { Rank } \\
\mathrm{x}^{-}\end{array}$ & $\begin{array}{l}\text { Total } \\
\text { ranks }\end{array}$ & & & & $\begin{array}{c}(\mathbf{r} \\
\text { prb })\end{array}$ & $\left(\eta^{2}\right)$ \\
\hline $1^{\mathrm{st}}$ & V.9. & rq.0. & r.1. & 10.0. & $0 \ldots$. & Y.OY & Sig. & .97 & $\because \vee 99$ \\
\hline $2^{\text {nd }}$ & r.7. & $11 .$. & $V_{.} \varepsilon$. & $r v . .$. & $r . .$. & $r .1$ & Sig. & .87 & $\cdot .7 r$ \\
\hline $3^{\text {rd }}$ & r.Y. & $17 . \cdots$ & $\vee . \wedge$. & $r q . .$. & $1 \ldots$ & $r . \leqslant 1$ & Sig. & .94 & $\because V 7$ \\
\hline $4^{\text {th }}$ & V.T. & r^... & r.\&. & $1 V . .$. & r... & r.19 & Sig & $\cdot \wedge \varepsilon$ & .79 \\
\hline $5^{\text {th }}$ & r... & $10 .$. & ^... & $\varepsilon \cdot \cdots$ & $\because \cdots$ & Y.7r & Sig. & $1 . \cdots$ & $\cdot . \wedge \mu$ \\
\hline $6^{\text {th }}$ & ^... & $\varepsilon . \cdots$ & $r .$. & $10 \ldots$ & $\because \cdots$ & r.71 & Sig & $1 . \cdots$ & .10 \\
\hline $7^{\text {th }}$ & r... & $10 \ldots$ & A.. & $\varepsilon \cdot \cdots$ & $\because \cdots$ & Y.TV & Sig. & $1 \ldots$ & $\because \wedge \varepsilon$ \\
\hline Skill & ^... & $\varepsilon \cdot \ldots$ & $r .$. & $10 \ldots$ & $\because \cdots$ & T.TE & Sig & $1 . \cdots$ & $\cdot . \Lambda \mu$ \\
\hline
\end{tabular}

Table (6) show that the value of computed $(\mathrm{Z})$ is higher than that of the tabulated (1.96) meaning that the value of Mann Whitney's test is significant i.e. the value of effect size ( $\mathrm{r}$ prb ) falls between (0.76) and (1.00) and the effect size is strong to very strong and the value of effect size $\left(\eta^{2}\right)$ falls between $(0.63)$ and (0.84) indicating that the effect size is large.

3/1/3 Presentation of results of the $3^{\text {rd }}$ hypothesis: 
Table (7)

Results of correlation and value of $(r)$ between results of games and footwork movement patterns of the experimental group and results of effect size using $\left(r^{2}\right) n=5$

\begin{tabular}{|c|c|c|c|c|}
\hline \multicolumn{4}{|c|}{ Correlation coefficient $(\boldsymbol{r})$} & \multirow{2}{*}{$\begin{array}{l}\text { Effect size } \\
\quad\left(r^{2}\right)\end{array}$} \\
\hline \multicolumn{2}{|c|}{ Physical tests } & $\begin{array}{c}\text { Results of } \\
\text { games }\end{array}$ & Significance & \\
\hline $1^{\mathrm{st}}$ & $\mathrm{cm}$ &.$\wedge \wedge$ & Sig. &.$V V$ \\
\hline $2^{\text {nd }}$ & sec. & -0.92 & Sig. & .10 \\
\hline $3^{\text {rd }}$ & sec. & $-\cdot . \wedge 9$ & Sig. & .199 \\
\hline $4^{\text {th }}$ & $\mathrm{cm}$ &.$\wedge \wedge$ & Sig &.$\vee \wedge$ \\
\hline $5^{\text {th }}$ & sec. & $-9.9 \leqslant$ & Sig. &.$\wedge \wedge$ \\
\hline $6^{\text {th }}$ & No. & .9 . & Sig & $\cdot \wedge 1$ \\
\hline $7^{\text {th }}$ & sec. & -.90 & Sig. & .9 \\
\hline
\end{tabular}

Tabulated $(r)_{(0.05)}=0.878$

Table (7) illustrate that the value of computed $(r)$ is higher than that the tabulated at (0.05) significance level meaning that the value of correlation coefficient is significant and the value of effect size $\left(r^{2}\right)$ falls between $(0.77)$ and (0.90) i.e. large effect size.

3/2 Discussion

Table (5) indicate that there are significant differences between means of ranks of the pre and post-measurements in physical abilities specific for footwork movement patterns and the results of games in the experimental group by Wilcoxon's test in favor of the post-measurement as the value of computed $(Z)$ is higher than

that of the tabulated and the value of effect size falls between $(0.80$ and 1.55) meaning that the effect is very strong and the value of $\left(\mathrm{\eta}^{2}\right)$ ranges from (0.905 to 0.949) meaning that the effect size is large. Also data in Table (5) concerning the results of games show that the value of computed $(\mathrm{Z})$ is higher than that the tabulated meaning that the value of Wilcoxon's test is significant. It is clear that the value of effect size $\left(r_{p r b}\right)$ is (1.55) meaning that the effect size is very strong and the value of $\left(\eta^{2}\right)$ is $(0.949)$ i.e. the effect size is large.

The researcher attributed this progress in the results of games in the experimental

Assiut Journal For Sport Science Arts 
group to the improvement and development of physical abilities specific for footwork movement patterns through applying the training program to the experimental group included a sort of quality exercises for physical abilities specified for footwork movement patterns such as flexibility, leg muscular ability, agility, speed endurance, reaction and balance in addition to movement patterns on the basis of scientific rate as exercises were similar to those of performing games in squash leading to stimulate emotions, necessities and intentions in young players to make more effort and to compete to achieve the best possible athletic performance.

This study was in agreement with that of Mamdouh Mohammed (2007) that the suggested training program for footwork movements for the research sample led to improve motor abilities specified for footwork movements and consequently, players became more quick and balanced in the court and hence, their performance effectiveness was increased in games. $\mathrm{He}$ insisted that exercises of footwork movements should be run together with physical technical and planning exercises and smarter coaches in the world have considered footwork movements and their relevant physical abilities.

This implication was in harmony with what stated by Spont Y. Cros (2007) that approximately $80 \%$ of technical faults occurred when performing squash hits resulted from lowering the quality of footwork movements rather than from techniques of performing hits and their motor descriptions. This was explained on the basis that hits would not be effective or accurate in respect of direction unless the player was existed in the suitable place and in time to hit the ball.

Basem Al-Maligi (2008)
indicated that footwork
movements were considered
the most important factors
contributing to the success of
the player in performing
various hits as the player used
footwork movements in
moving to try to use the ball
very well together with taking
the suitable steps for the
distance he could run to
approach the ball that to be
available for his hits.
\begin{tabular}{llr}
\multicolumn{3}{c}{ Basem Al-Maligi (2008) } \\
indicated that footwork \\
movements & were considered
\end{tabular} the most important factors contributing to the success of the player in performing various hits as the player used footwork movements in moving to try to use the ball very well together with taking the suitable steps for the distance he could run to available for his hits. 
Table (6) demonstrate that there are significant differences between the experimental and control groups in the postmeasurement in footwork movement patterns and the results of games in favor of the experimental group.

The researcher attributed the progress of the experimental group to the control group in variables under investigation to the effect of the training program of the experimental group that was planned and rated scientifically according to the reference survey of researches and scientific references in the field of racket sports in general and squash in particular as the program planned and rated scientifically and correctly affected positively the physical and skill performance of the players as the researcher rated exercises related to physical abilities specified for movement patterns on the scientific basis and in line with rating the training program and in conformity with the preparation period of the training season, he rated movement patterns similar to the performance of games leading to stimulate the experimental group to work and to make the best effort for superiority. These implications were in agreement with Ali Jihad (2014) who thought that planning training and physical programs and footwork movement patterns and skill programs were the most important factors helping make the champion and maintain the stabilization of the level of players and repetition of winning championships.

This study was in agreement with Shawkat Jaber (2005) confirmed that physical abilities specified for footwork movements led to cause the level of the players to increase in physical and skill abilities specified for footwork movements and the results of games.

This was the true reason for the superiority of the experimental group to the control group in all tests.

Table (7) present that there is a correlation between the development of footwork movement patterns and the improvement of the results of games of squash young players meaning that a close relationship between footwork movement patterns and the results of games. The 
researcher attributed that this relationship was not the result of chance but it was the effect of developing physical abilities specified for footwork movement patterns and the proper scientific ration as it was considered in exercises that all footwork movement patterns should be similar to those of the method of performing games and in all directions of the court and consequently affected positively the improvement of the results of the games and the program achieved purposes for which it has been established.

This study was in agreement with Riham Mahmoud (2008) emphasized that footwork movements actually affected the results of games particularly movement towards the left direction in respect of the sport of squash as such movements were difficult and that the ball has been often directed towards that direction to have the players to fall in movement faults to lose the game.

This study was in agreement with Hamdy Aliwa (2010) clarified that training programs specified for footwork movements such as speed of reaction, muscular ability, flexibility, agility and endurance with its types exercises could help players win points in the game leading to end the game for their favor because players could meet special training loads than players who did not consider footwork movements nor patterns related to them.

4/0 Conclusions and recommendations

\section{Conclusions}

The researcher achieved the following conclusions:

- Developing physical abilities specified for footwork movement patterns (flexibility, agility, muscular ability, speed endurance, speed of reaction and balance affected positively the improvement of the results of games for the experimental research sample.

- There are significant differences at 0.05-level between the two postmeasurements of the experimental and control groups in footwork movement patterns and the results of games in favor of the postmeasurement of the experimental group.

- There is a correlation between developing footwork movement patterns and improving the results of games. 
- Training on footwork movement patterns helps cover the whole court quickly and cover the opponent hits.

4/1/5 Training on the proper footwork movements protects the player from technical and judging errors which are numerous in games of young players and helps economize and organize effort on games of the match.

- Training on footwork movements helps cover the overall court and the opponent hits.

4/2 Recommendations

4/2/1 Developing physical abilities specific for footwork movement patterns should be considered and their rated training programs should be placed.

- When training and placing programs in different periods of the season, movement patterns should be considered.

- Coaches should consider individual differences among players in physical abilities of footwork movements for each player separately and scientific basis and fundamentals should be considered when training.

\section{References:}

1- Ahmed Sobhi Salem (2004):

Effect of mental training on developing some motor skills in table tennis young players. Ph.D. Thesis, Faculty of Physical Education for Boys, Alexandria University, Alexandria University, Alexandria University.

\section{1- Ehab Saber Ismail} (2013): Effect of footwork exercises on accuracy of performing some attacking skills in squash players. Ph.D. Thesis, Faculty of Physical for Boys, Zagazig University.

\section{2- Basem Mustafa Al-} Meligi (2008): Developing footwork movements and their effect on speed and accuracy of performing some basic skills in table tennis young players. M. Sc. Thesis, Faculty of Physical Education for Boys, Alexandria University.

\section{3- Hamdy Mohammed}

Aliwa (2010): Measuring Electrical activity of leg muscles of squash players during moving backward as an indicator to place a qualitative training program to develop the reaction factor. M. Sc. Thesis, Faculty of Physical Education, Minya University.

\section{4- Riham Mahmoud}

Mohammed (2008): An analytical study on footwork movements in squash and judo sports and their effect on the results of games. M. Sc. 
Thesis, Faculty of Physical Education, Minya University. 5- Shawkat Jaber Radwan (2005): Effect of developing some physical and skill abilities specified for footwork on results of games in table tennis. Ph. D. Thesis, Faculty of Physical Education, Suez Canal University. 6- Ali Jihad Ramadan (2014): Squash (Teaching, Training, Judging). Al-Furat Press, Bagdad.

7- Mohammed

Ahmed Abdullah (2007): Scientific Fundamentals in Table Tennis and Measurement Methods. Ayat Bookshop, Zagazig. 8- Mamdouh Mohammed Ahmed (2007): Effect of a training program to improve some motor abilities specified for footwork movements in young players in ground tennis. M. Sc. Thesis, Faculty of Physical Education, Tanta University.

9- Philip yarrow: Second Edition Squash steps to success human kinetics (2010).

10- Spont . y .Cross : "Yes Squash" percept motor skills (2007). 